\title{
Two-dimensional Gap Analysis: A Tool for Efficient Conservation Planning and Biodiversity Policy Implementation
}

\begin{abstract}
The maintenance of biodiversity by securing representative and well-connected habitat networks in managed landscapes requires a wise combination of protection, management, and restoration of habitats at several scales. We suggest that the integration of natural and social sciences in the form of "Two-dimensional gap analysis" is an efficient tool for the implementation of biodiversity policies. The tool links biologically relevant "horizontal" ecological issues with "vertical" issues related to institutions and other societal issues. Using forest biodiversity as an example, we illustrate how one can combine ecological and institutional aspects of biodiversity conservation, thus facilitating environmentally sustainable regional development. In particular, we use regional gap analysis for identification of focal forest types, habitat modelling for ascertaining the functional connectivity of "green infrastructures", as tools for the horizontal gap analysis. For the vertical dimension we suggest how the social sciences can be used for assessing the success in the implementation of biodiversity policies in real landscapes by identifying institutional obstacles while implementing policies. We argue that this interdisciplinary approach could be applied in a whole range of other environments including other terrestrial biota and aquatic ecosystems where functional habitat connectivity, nonlinear response to habitat loss and a multitude of economic and social interests co-occur in the same landscape.
\end{abstract}

\section{INTRODUCTION}

Today, it is widely accepted that landscapes should be managed in a sustainable manner, meaning that both production and biodiversity conservation should be considered. The 1992 Convention on Biological Diversity has not only focused international attention on the concept of biodiversity but has also set expectations that the signatory states will establish objectives and mechanisms for local implementation. According to these international agreements, EC legislation and national policies, the maintenance of biodiversity is currently an agreed value in Sweden. Consequently, there is a common vision that biological diversity should be maintained, and quantitative political targets have been formulated for lakes and waterways, wetlands, forests, cultural, mountain, and urban landscapes (1). In the Swedish Forest policy, the ultimate environmental goal is even interpreted as the survival of viable populations of all naturally occurring species (2).

Maintaining biodiversity requires a wise combination of protected areas, management and restoration to create and maintain representative and functionally connected networks of all habitats $(3,4)$. However, recent analyses in northern Europe suggest that the existing quality and amount of habitat networks are insufficient (5). The tool that has been employed is gap analysis, which can be defined as the identification of disproportionate scarcity of certain ecological features in a management unit, relative to representation to a larger region surrounding the management unit (6). Using this approach, in Sweden Angelstam and Andersson (7) argued that a combination of conservation, restoration and even re-creation of habitats is needed to accomplish the political goals of biodiversity maintenance in areas with a long landuse history. Similarly, in Estonia, Lõhmus et al. (8) identified gaps in the amount of forest of different representative types needed to provide sufficient habitat for viable population of species with different habitat affinities.

However, the total amount of habitat found available in a regional gap analysis does not take into account the level of functionality of the habitat networks (9). Habitat Suitability Index (HSI) models for specialized and areademanding focal species is an approach, which takes further the results of such regional gap analyses (4, 10-12). HSImodels are useful tools for assessing the current status of the networks of different habitat types, as well as for planning of restoration and re-creation needed in order to accomplish the defined policy goals. Unfortunately, complete sets of parameter values for focal species for all habitats are not available to the extent needed to cover the variety of habitat types found in whole landscapes. However, for forest taxa the level of knowledge is rapidly increasing. For example studies of both the quantitative habitat needs of areademanding specialists $(13,14)$ and the indicator value of these species $(15,16)$ are appearing. Angelstam et al. (9) used quantitative knowledge about the requirements of specialized forest birds listed in the EC Birds Directive to estimate the size of planning units for the assessment of habitat networks aimed at maintaining biodiversity. The estimated mean minimum size of planning units where suitable habitat dominates the landscape was about 40000 ha, while in managed landscapes with a minimum amount of habitat the unit size averaged 250000 ha. By contrast, the size of individual conservation areas such as woodland key biotopes and protected reserves from which habitat networks can be built in a managed matrix was $1-1000$ ha. To maintain biodiversity, there is hence clearly a need to extend the spatial and temporal scale of management and planning from the stand scale to that of landscapes within large management units.

Since the above analyses concern quantitative and spatial dimensions of the land cover within landscapes, the combination of regional gap analysis and analysis of functionality using HSI-models can be summarized under the single expression "horizontal gap analysis". However, biodiversity conservation, and sustainable development in general, largely depend on the "vertical" dimension from policy to implementation.

Defining a social-ecological system is a critical step on the path towards achieving sustainable development of that system $(17,18)$. Considering that not all the parts of the world are equally suitable for use as units of sustainable 
development, it is argued that sustainability will depend to some extent on the possibilities of human steering (17). In order to achieve effective steering, a consensus-building strategy should be aimed at, which means that a majority of the actors involved in the unit should agree on sustainable development goals and measures to be taken to achieve them (17). However, human actors-individuals, corporations, governments - always pursue a spectrum of "interests" concerned with their own viability in a world full of other actors (human or nonhuman) and self-organized systems, each of which is in turn pursuing its own "interests" in interaction with others (19). Therefore, ideally development is shaped by conflict and compromise of interests of the different participating systems (19).

The social systems can be considered as hierarchical, described both structurally and functionally, and should cover the characteristics that can be changed (i.e. be steerable) $(17,18)$. The following steps are important in defining such a system: i) identification of the ecological system; ii) assessing people involved directly and indirectly, at present and in the future; iii) delimiting the social-ecological system in time and space; iv) describing subsystems, values, constraints, and relations (17).

Social-ecological systems in a political ecology approach combine the concerns of ecology and political economy to represent an ever changing dynamic tension between ecological and human change (20). Political ecology should incorporate the diversity and dynamics of life. The ecological services and resources that are available at a given time and place determine the alternatives that are available for people. This set of alternatives shapes politics, economics, and management of these ecosystems (20). The environmental side of the system may be defined by describing characteristics of an area (e.g. size, location, geographic characteristics and elements of biodiversity such as the species, habitat structure, and processes $(21,22)$. The societal responses to environmental issues are expressed on the institutional side of the socialecological system. The institutions include, but are not limited to beliefs, norms, relationships, property rights, and agencies $(23,24)$.

Only some combinations of both ecological and political dimensions of biodiversity conservation may lead to fulfilment of the objectives set by the actors of relevant social-ecological systems. If treated in isolation, neither of these fields will lead to accomplishment of expected results $(25,26)$. Without being successfully integrated into the political process, scientific knowledge cannot become a part of successful natural resource management $(27,28)$. Effective biodiversity conservation will not take place unless political will is generated and social and economic systems modified (29). Therefore, in the search for gaps in biodiversity conservation, both ecological and political dimensions must be considered.

In this paper, we suggest how ecological and political aspects of biodiversity conservation should be combined and used in designing an approach using different analytical tools for maintaining biodiversity and facilitating sustainable development in general. While the regional gap analysis and habitat modelling literally takes place on the face of the earth and is horizontal in nature, the political aspects of the conservation of landscape elements can be considered as vertical, as they concern the success of policy implementation (30). Potential units for assessment of horizontal and vertical gaps range from forest management units, private forest in villages, municipalities, to the planning units based on catchment boundaries envisaged in the EC water framework directive (31). The latter would require dramatically improved harmony between the biophysical, socioeconomic and political components of a landscape $(32,33)$.

We describe in what way the natural and engineering sciences are needed to build and refine tools for assessment of today's landscape qualities and for strategic conservation planning using regional gap analysis and Habitat Suitability Index (HSI) models for habitat specialized focal species. We then discuss the role of social sciences for assessing the success in the implementation of biodiversity policies in real landscapes. We suggest how a Decision Support System that integrates horizontal and vertical aspects of biodiversity conservation can be developed for planners and managers within forest companies, the national board of forestry, counties, and municipalities. Finally, we stress the need for an active adaptive management approach.

\section{HORIZONTAL GAP ANALYSIS}

\section{Regional Gap Analysis}

Gap analysis may mean several things. We focus on the gaps in the amount of the different representative forest habitats that can be estimated to be needed in the long term to maintain viable populations of the naturally occurring species, which cannot survive in the regular managed landscape. Gap analysis thus aims at identifying the most endangered types of habitat in an ecoregion. What are the long-term needs of protected areas for different forest types? How much of those exist today? How much of what exists is protected? Is there also a need for rehabilitation, and even re-creation of habitats?

As an example, a regional gap analysis for the counties Dalarna and Gävleborg in central Sweden can be used (12). To provide numerical estimates of the regional gaps in the amount of existing as well as protected areas of forest types with high conservation value, knowledge about forest ecology, quantitative requirements of focal species and the past and current land cover was used in the following steps:

- A. Estimate the amounts of the various types of potential forest vegetation based on modelling of the distribution of different natural forest disturbance regimes, and on knowledge about the age distribution within these different disturbance regimes (34).

- B. Estimate today's amount of the naturally occurring forest types defined in A using remote sensing data calibrated with forest-stand data.

- C. estimate the amounts of representative forest types needed to maintain viable populations of the most demanding species based on the appearing knowledge about population's nonlinear responses to habitat loss (e.g. (35))

- D. Estimate the difference between B and C, where a negative value implies a gap in habitat area and a need for habitat rehabilitation and/or re-creation. To illustrate the biased loss of forests on different site types the results should be divided into those caused by loss of forest cover by clearing of past forests, as well as loss of different forest types on today's forestland. Comparisons among regions allow for analyses of differences in representativity.

- E. Estimate how much of the existing representative forest types with gaps are protected today in nature reserves (and thereby identify protection gaps), as well as how much is included in current plans for future protection. 
When made within a particular region, the forest types for which gaps have been identified also need to be evaluated as to the extent to which they actually fulfil the function of providing habitat networks for species, which are specialized on these kinds of forest. This evaluation often results in the need of strategic planning for acquiring additional protected areas, as well as management and rehabilitation of forest areas to improve the selected green infrastructure in focus within the landscape.

\section{Habitat Suitability Index Modelling Using Focal Species}

In order to evaluate the extent to which existing habitats also are functional there is a need to develop procedures for assessing networks of conservation areas, and subsequently use the results as a basis for planning of conservation and restoration measures. There is a multitude of factors affecting the distribution and abundance of a species. For operational, spatially explicit, planning purposes, however, some simplification is essential. Habitat suitability index (HSI) modelling consists of combining spatially explicit land-cover data with quantitative knowledge about the requirements of specialized species and building spatially explicit maps describing the probability that a species is found in a landscape $(4,10,36)$. With such data on a suite of focal species, a series of predictive landscape models for the different vegetation types in a landscape can be built. This requires quantitative information on the habitat requirements of the species for at least 3 spatial scales. An example of such modelling is presented in Figure 1.

First, the land-cover of vegetation for a particular focal

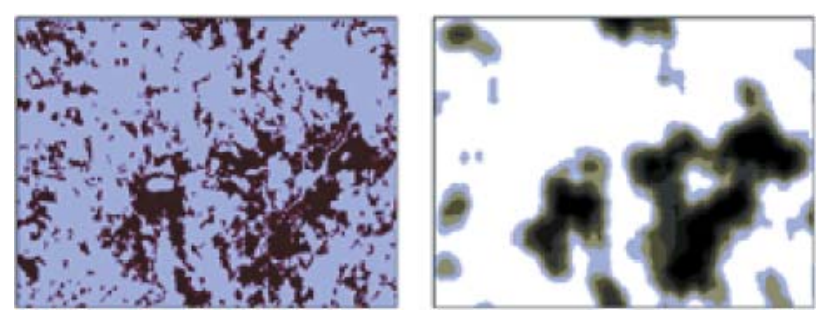

Figure 1. With appropriate land-cover information (left), knowledge about the habitat requirements of appropriate focal species and Habitat Suitability models, probability maps for areas of high conservation value can be predicted (right) and compared with the individual forest owners management plans.

species (LANDCOVTYPE) must be mapped with sufficient detail to match the operational scale of individuals. In northern Europe this is becoming available, for example, from inventories of key biotopes (37) and the Baltic Forest Mapping Project (M. Walsh, pers. comm.). The habitat for a given species is often composed of a combination of such land-cover types. Second, the necessary amount of patches of suitable land-cover types must be defined for an individual (HAB_PATCH). To define the patches clearly, the species chosen for HSI modelling should have a high degree of specialization on certain types of vegetation cover. The occurrence of a species is affected mainly by the extent and spatial distribution of natural or anthropogenic disturbances, which either create or destroy the habitat. In managed forest landscapes, the extent and magnitude of such disturbances are mostly a result of silvicultural systems, ownership pattern (large/small) and socioeconomic situation. Third, species have requirements at the population level. The number of habitat patches and their spatial distribution make up connectivity (38). Several studies have investigated the relative importance of habitat amount and configuration for animal populations. Simulation studies have predicted varying effects of habitat fragmentation on extinction thresholds, depending on the mechanisms assumed by the different models $(39,40)$. Simulations by Fahrig $(35,39)$ have predicted that habitat loss is more important than habitat configuration. Additionally, empirical studies from North America have shown that forest cover had a major effect on the distribution and abundance of breeding birds, while configuration did not explain much more (41-43 but se 44). This suggests that the proportion of a landscape made up by sufficiently large habitat patches (HAB_PROP) could be used as a single measurement of landscape suitability, and thus as a surrogate for connectivity, at the population scale (4, 40). Moreover, if patches are ephemeral, for example a certain successional stage lasting only a few years or decades (HAB_DUR), the landscape must be large enough to contain a stable patch dynamic of this particular stage (45). In summary, a HSI model for a given species (HSI_SP) is made up of all the variables described above and pictures the relative suitability for the species across a given landscape.

HSI_SP $=f[($ LANDCOVTYPE); (HAB_PATCH); (HAB_PROP); (HAB_DUR) $]$

Note that this is not a mathematical expression, but rather a summarized description of the information needed for assessing the suitability of the landscape using neighborhood analysis techniques in Geographic Information Systems (see below). With this approach the maintenance of viable populations of all "focal" species, and their associated species, will require the integration (i.e. not the sum) of the habitats of all focal species' HSI_SP. In order words, the network of each representative habitat (one or several land-cover types) often must be analyzed and managed as a separate infrastructure.

The procedure suggested above provides a general basis for the planning and assessment of habitat networks. However, the development of practical tools using such a suite of focal species is subject to some level of uncertainty depending on the level of knowledge on the different parameters included in the model. Angelstam et al. (9) evaluated the level of knowledge available for using a suite of specialized forest birds as focal species. While the requirements of individuals at the patch scale are relatively well known for most species, there is an obvious lack of knowledge when it comes to the requirements of viable populations at the scale of landscapes and regions. Another factor influencing the development of practical tools is the quality of land-cover information available to the planner. Land-cover maps are produced for a multitude of applications and are therefore not necessarily appropriate for mapping all relevant environments with sufficient thematic and spatial resolution. For example, depicting the habitat of species dependent on dead wood (e.g. many species of woodpeckers, beetles, and wood-decay fungi) requires spatially explicit data on the occurrence of this resource across the landscape. Such data are not currently available from forest management maps or classified satellite images, and therefore additional ancillary data need to be collected if the aim is to conserve biodiversity.

Special attention should be paid to the selection of the species whose requirements are used for conservation planning and assessment. Ideally, these focal species should be chosen 
among the most demanding or sensitive species for a range of landscape attributes (46). Since the most demanding species vary among habitats and scales, the suite of focal species should include representatives from several different taxa (47). For each species, the models should be validated in order to test how reliably one can predict occurrences of the focal species in real-world landscapes (36). This validation should be made with independent data and, preferably, in landscapes containing a wide range of amounts of the relevant habitats and associated resources. In forest, such landscapes are found in the eastern part of the Baltic Sea region, where forest ecosystems have not been managed as intensively as in Fennoscandia (48). In order for the habitat models to provide a tool for conservation of entire communities, one should also test the indicator and umbrella values of the proposed focal species. In forest environments, there is evidence for the indicator value of many specialized species, for example among birds (15) and lichens (49). Moreover, there is growing interest in umbrella species, i.e. species whose conservation provides also protection to numerous co-occurring species $(16,50,51)$.

\section{Sensitivity Analysis}

Our approach to spatially explicit strategic conservation planning involves many processing steps and data sources (9). The decisions to be taken will, among other things, depend on the HSI models, processing models, data sources, and the decision-making process being used. The sources of errors and the variability of parameter values for the different variables can be separated into at least technical factors, such as sensors and selection of algorithms; abiotic factors, such as the variation of terrain elevations; biotic/ecological factors, such as the forest ecology and natural disturbance regimes; and anthropogenic factors, such as land use and population densities.

All these factors interact in a large nonlinear system. In order to study the relative importance of each part of the system, Monte-Carlo simulation techniques may be used. This technique has earlier been used with success within the GIS field (52) and it has also been suggested as a generic method for error propagation and uncertainty studies (53). To evaluate the results of such sensitivity analysis, its impact on the decisions must be studies. One approach to this, is to use expected utilities as measures (54). In this approach, the utility of each possible decision is estimated, and using probabilistic estimates from the Monte-Carlo simulations, the overall expected utility can be estimated.

\section{VERTICAL GAP ANALYSIS}

In many parts of Europe, the successful implementation of policies related to the maintenance of forest biodiversity is an important aspect of sustainable regional development. This requires cooperation among many actors with different interests, attitudes and competencies on different levels of society (scientists, small private landowners, big corporations, local and regional authorities, national government, and EC policy makers) $(55,56)$. The policy process is about goal formulation, mobilization of resources, organizational solutions and prioritizing options for land use. Due to this complexity, the question may be raised as to what degree forest biodiversity policies can be implemented. This is an urgent field of research and development, which needs to be addressed for moving towards a more sustainable ecological future. This also requires a transdisciplinary approach to include both natural and social sciences $(18,33,57-59)$. To understand this complex reality, policy- and implementation research is of vital importance $(60,61)$. It can help us in identifying, describing, and interpreting troublesome obstacles as well as vital forces in actual implementation processes. This empirical knowledge is important for developing and improving different kinds of recommendations, for instance policy formulations, implementation strategies, organizational solutions and decision support systems. In this section, we present a logic for identification of failures/gaps in implementation of national forest programs. However, this approach can be adjusted to serve the interests of analyses in particular regions or even individual issues of biodiversity conservation efforts.

\section{Gap Analysis at the Level of Institutions}

Securing viable populations of the most demanding species in each forest environment, as well as restoration and recreation of forest environments is highly dependent on those in charge of management of natural resources $(62,63)$. Despite the fact that in a structured way the issue of national forest programs has been addressed only recently (64), administration of forest resources in each country has for long been carried out in a form which can be considered as a national forest program. Worrell (65) in discussing the principles of forest policy indicated that forest policy has in 3 major steps: goals, means, and process. In terms of goals, he considered the problems that society faces in deciding what purposes it wants its forest resources to serve. The means, as stated by the same author, include various possible techniques, which might be used by the society to implement policies (65). Merlo and Paveri (66) indicated that policy process consists of analysis of problems, followed by setting of goals and policy tools, and implementation.

A contextual approach to policy instruments as well as economic development literature provide that key actors (including the state) play a crucial role in combining their interests on a national level (67-69). The same concept may be applied to the forest sector while setting forestmanagement goals and objectives. In the simplified national forest program theory, if there are issues of concern, key actors in the sector address them in policy objectives, based on which, policy instruments are designed. It is assumed that policy instruments, as carried out by implementing institutions, would essentially eliminate specific problems in the sector.

For the purposes of this theory, it may be assumed that all stakeholders, both national and international, governmental, and private, having some interest in forest resources, compete among each other in order to satisfy their own needs and expectations. As a result of this friction, a set of national (as well regional or local) forest administration objectives is drafted. The objectives may be long-term as provided within official documents or short term, as identified by the stakeholders in any other form. Issues of concern may also mean different interests or expectations. The idealistic approach adopted in this theory assumes that after the program has completed one cycle and was implemented, none of the related parties will express any issues of concern and interests of all stakeholders will be satisfied unless new needs and expectations arise. Of course, the above situation will never take place in reality. Still, however, it may serve as an ideal vision to strive for by national forest program design when evaluating the success of actual forest programs. In the 


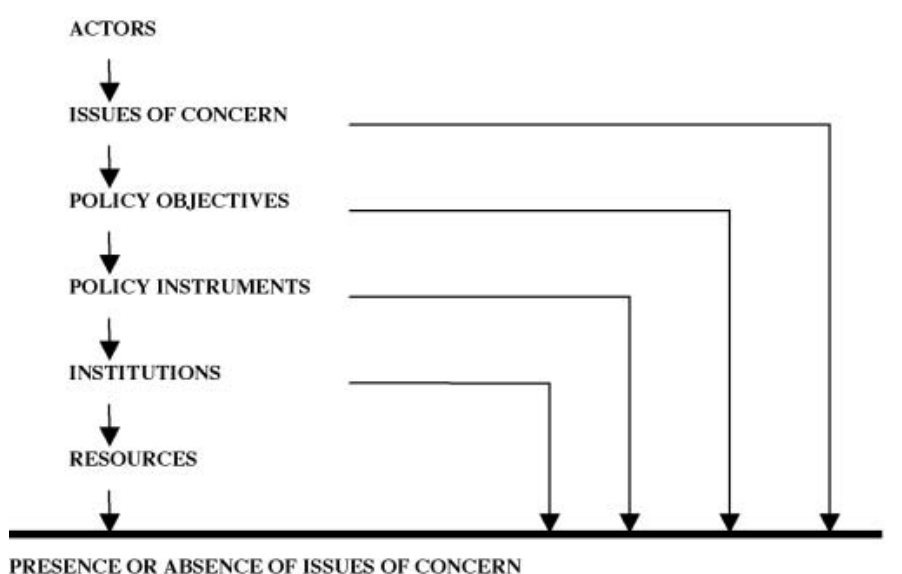

Figure 2. Framework for institutional gap analysis (84).

real world, the national forest program is an iterative process, during which the stakeholders prioritize the set of objectives, and commonly produce only the second best (or sometimes even hardly tolerable) outcome for some of the stakeholders. Therefore, the nationally adopted set of forest policy objectives is a result of compromise (not consensus) made between various interest groups, and is usually based on the political power of those groups. Even in the case of fulfilment of these objectives, a new negotiation process will start in order to adjust forest sector development towards satisfaction of previously suppressed interests.

In the subsequent step of the forest program, policy instruments are chosen in order to achieve objectives of forest-resource administration. In order to put the above instruments into practice, implementing institutions are created or existing ones charged with responsibilities. In the longterm, representatives of implementing institutions also may become significant stakeholders in the sector, on their own influencing the formation of forest policy goals. However, in order to maintain the clarity of this design, the objectiveinstrument-institution logical relationship is presented. According to this design, institutions deal directly with forest resources (or those directly managing resources) and do their best to achieve national forest administration objectives through the implementation of policy instruments. Besides the changing interests of stakeholders, national long-term or short-term objectives may be modified by other factors, which are not directly related to human activities. These factors are directly affecting forest resources and include, but are not limited to, insect and disease outbreaks, forest fires, and disastrous storms.

Figure 2 presents a logic for program evaluation, or otherwise, the analysis of gaps in forest policy processes of the national, regional or local forest politics. In an ideal situation, direct satisfactions of the needs or expectations of the stakeholders, e.g. objectives to maintain biodiversity in forests, as well as to assure continuous supply of timber, would follow the issue-objective-instrument-institutionresources logical relationship and lead to elimination of the issues of concern. However, the above may take place only with few interested parties and abundant resources. In the real-life situation, gaps may occur at any stage of the above program. Due to the conflicting interests or other reasons, some of the issues important to the stakeholders will not be even addressed in the policy objectives. Even if addressed in policy objectives, implementation tools may not be developed. If policy implementation tools are selected, they may not be implemented due to the lack of institutional capacity. If all of the above exists, issues of concern may still be present due to the factors outside of human influence or factors external to the influence of the sector. Any of the above gaps in a national forest program will lead to dissatisfaction of individual or group of stakeholders or difficulties in implementing the policies.

\section{Types of Questions in a Forest Management Unit}

Are the policies consistent?

An important aspect of the policy-process is, of course, the stage of goal formulation. Unclear goals and/or goal conflicts often cause problems in the implementation stage of the policy process. This is particularly important in policy fields, where rules are created by a large number of actors. In the policy area of forest biodiversity, the policies which together form the important rule structure are complex, with components on the national level (the environmental goals of SOU 2000 (1), the Forest Policy, including the advisory role of the National Board of Forestry and its field organization.), the EC-level (the Birds, Habitat and Water Framework Directives) and global level (the Convention of Biological Diversity). The following empirical questions deserve to be addressed: Are these policies clearly formulated and consistent? Are important aspects of forest biodiversity missing in those documents?

\section{Application of HSI models in real world case studies}

In Sweden, the ownership pattern differs dramatically between the North and the South (70). This affects the number of forest owners per unit area, which varies up to 1000-fold among landscapes (National Board of Forestry data), as well as for their attitudes towards policies (e.g. 71). Hence, our hypothesis is that the main factors among landscapes affecting the success of implementing strategic conservation plans are the number of owners per unit area, and the types of decisionmakers involved in this process.

The application of HSI-modelling using focal species has several limitations. There is neither a complete set of HSI models representing even major habitats/focal species in a landscape $(9,12)$, nor are they validated in the field and the long chain of steps quality assured. Moreover, the application of such policy implementation approaches may be at odds with perceived local needs and views (e.g. 71). It is therefore necessary to evaluate potential "vertical gaps" the application of this approach for biodiversity policy implementation by top-down conservation planning in practice. This can be done using a case study approach whereby habitat types of local interest are subject to HSI-modelling using focal species or properties. The spatially explicit habitat data from landowners and planners, and the HSI models as planning tools can then be combined to guide the different landowners management decisions. Which forest stands should be part of the network of conservation areas? Where might restoration and re-creation be needed in order to maintain and restore representative and well-connected "green infrastructures" for the maintenance of forest biodiversity.

\section{Evaluation of policy implementation}

In order to study the actual implementation stage of the strategic conservation planning algorithms, we suggest a bottom-up analysis with a multi-method design (documents, interviews, etc.) $(61,72-74 a)$. This means mapping so-called implementation structures, starting from the bottom, i.e. from individual owners of land, and up through the village, 
landscape, and different interest groups. We focus here on owners' priorities and strategies in land use and what types of cooperative networks they have. We then go on to interviewing persons and institutions, which have been identified as important, in order to map networks/implementation structures $(72,73)$. The focus should be on problems/gaps as well as good examples of cooperative implementation, in particular by searching so called advocacy coalitions (61). The interviews should start with questions about landowners' background, strategies and priorities and then continue with 3 types questions (74):

- How do the implementing actors understand policies and directives, and the planning tools?

- Do they have capacity to act, that is resources, competence, etc?

- Do the implementing actors feel that they have the possibility to influence policies and directives, and do they feel motivated to act in line with those or are they opposed to them?

\section{DISCUSSION}

\section{Integrating Natural and Social Sciences}

Gap analysis and Habitat Suitability Index (HSI) models for specialized and area-demanding focal species provide interesting complementary approaches to evaluate and maintain functional habitat networks $(4,9,12)$. By combining spatially explicit habitat data from landowners and planners and Geographical Information Systems into HSI models for focal species, planners are provided with a tool to guide land-management decisions. However, this requires that planners have adequate knowledge of the components of biodiversity, have appropriate land-cover information and can use the GIS tool for modelling, communicate the results to different actors and decision-makers as well as function within appropriate legal and institutional frameworks. Sandström et al. (83) made deep interviews with planners in Swedish cities and found that neither of these requirements was at hand. To rectify this situation dramatically improved harmonization between the biophysical, socioeconomic, and political components of landscapes is needed. As pointed out by Vogt et al. (75) integration between natural and social sciences is essential for effective management of natural resources such as different components of biodiversity.

Landscapes can be viewed with both an anthropocentric and a species-oriented perspective. For the assessment and planning of representative habitat networks for the maintenance of biodiversity both views are needed at multiple spatial scales. Using the compositional dimension of biodiversity, i.e. species, this means that managers need to understand that different species have different habitat affinities as well as different quantitative requirements, and that viable populations need more habitat than what is found in one patch. Hence, the successful maintenance of all representative habitats in the environment can be viewed as a series of partly overlapping and complementary "green infrastructures" in the landscape, each of which has different properties to which species are adapted. The quantitative extent of such habitat networks depends on the requirements of species. For example, an old-growth forest specialist species with large area requirements will need more habitats than a generalist with small area requirements.

From the applied ecologist's view there is a need to know more about the planning process (26). This involves both an adequate understanding of the tools available to planners, their, cost and other constraints. It also requires certain pedagogic skills to explain the practical consequences of maintaining viable populations. Different species do not only use different habitats, but they also have quantitative requirements in a wide range of space and time domains. Hence, habitat requirements must be satisfied at the scales of individuals, populations, and metapopulations, ranging from local to regional landscapes. This idea is consistent with the proposal of Vogt et al. (75) to collect and analyze data at several scales (habitat patch, neighborhood, residential area, etc.) in order to link natural and social sciences in the planning process.

\section{Education and Decision Support Systems}

Sandström et al. (83) evaluated the extent to which Swedish urban planners have sufficient knowledge and appropriate tools to plan for the maintenance of biodiversity by providing green spaces of sufficient amount and quality. Three planners in each of 6 large cities were interviewed with respect to their interest, ability and knowledge about planning for functional networks of green spaces. The unanimous view was that they are interested, but are limited by knowledge, personnel, and technical resources. In this case, an important tool appears to be vocational training to improve the planners' knowledge, as well as a better integration of natural and social sciences in education, and policy implementation in general.

To mitigate such problems, Decision Support Systems (DSS) are a useful tool consisting of a collection of integrated models, data and processes, which can be used to develop scenarios and obtain support for complex decisions. In accordance with current software engineering paradigms, computerized processes will be implemented as web services. A web service is here defined as "a software system identified by an URL, whose public interfaces and bindings are defined and described using XML. Its definition can be discovered by other software systems. These systems may then interact with the Web service in a manner prescribed by its definition, using XML based messages conveyed by Internet protocols" (76). However, for full exploitation of the potential of such web services, an underlying spatial data infrastructure must be in place. Such an infrastructure consists of services for data supply and basic processing services. The INSPIRE initiative of the EC is an attempt to create such an infrastructure (77). Using the concept of web services, a variety of service providers may be connected for a certain DSS. For instance, different service providers may provide services for different HSI models, providing possibilities for flexible design of the DSS as well as competition and a high level of specialization among service providers.

\section{Active Adaptive Management}

Science should develop tools that alleviate the communication gaps between policy and practice. The adaptive management concept appears to be a well-developed candidate for an operational environmental management process (63). Adaptive management is a dynamic approach to ecosystem management in which the effects of treatments and decisions are monitored and used, along with research results, to modify management on a continuous basis, to ensure that objectives are being met (78). Bormann et al. (79) pointed 
out that this approach helps to manage complex natural systems while building on learning - based on common sense, experience, experimenting, and monitoring, i.e., by adjusting practices based on what was learned. Adaptive management seeks to accelerate learning and adapting through partnerships based on finding common ground where managers, scientists, and citizens can try to learn together to create and maintain sustainable ecosystems (79). Existing knowledge, technology, inventory, and goals are used to develop plans, which are followed by the actions taken (80).

For the planning activity in the adaptive management process for environmental management 4 steps are identified: problem defined; alternative development; alternative selection; and authorization to implement (63). The planning stage results in decisions about goals and constraints, and the action stage determines how, where, and when to implement activities to achieve the goals and adhere to the constraints (63). The results and actions are carefully monitored and evaluated (80). What variables are monitored and when, how, and where they are monitored depend almost entirely on the hypotheses created in the action stage and on the type of actions determined to be necessary to test the hypotheses (63). An analysis of all adaptive results should be compiled periodically and forwarded to the next higher planning level for corrective change leading to new actions (63). At each cycle the results of evaluation activity are fed back to the planning activity so that adaptive learning can take place (63). An adaptive management process is ideally suited for citizen-agency interactions because communications between managers and the public do not occur in isolation from one another (80).

The active use of adaptive management can increase the overlap between social values and ecological capacity when managers produce information for future decisions at the same time as they produce other resources and amenities, and when managers, scientists, and citizens see learning as common ground (79). Ecological sustainability requires a diversity of learning strategies and requires managers and citizens working directly with scientists, in close cooperation, to provide a holistic view of the desired conditions and positive, creative responses to change. This common ground may be found only when scientists accept management as a dominant ecosystem process and managers recognize that increased information and analysis are necessary to manage natural resources in a sustainable way $(79,81,82)$.

\section{CONCLUSION}

We suggest that cooperation between natural and social sciences in the form of 2-dimensional gap analysis as presented here, may prove to be an efficient tool in successful conservation planning and biodiversity policy implementation. The concept links horizontal issues of biological relevance with vertical issues of societal nature. In particular, regional gap analysis for identification of focal forest types, Habitat Suitability Modelling for ascertaining the functional connectivity of "green infrastructures", and recognition of institutional obstacles in implementation of forest policies are important tools. This approach may be applied in a whole range of other environments including other terrestrial biota and aquatic ecosystems where functional habitat connectivity, nonlinear response to habitat loss and a multitude of economic and social interests co-occur in the same area.

\section{References and Notes}

1. SOU 2000. The Environment of the Future - the reponsibility of everybody, (Framtidens miljö - allas vårt ansvar). Slutbetänkande från miljömålskommittén. Statens Offentliga Utredningar 2000:52, Miljödepartementet, Stockholm, Sweden. (In

2. SOU 1992. Forestry Policy of the 2000 Millenium. (Skogspolitiken inför 2000-talet). Statens Offentliga Utredningar 1992:76, Jordbruksdepartementet, Stockholm. (In Swedish).

3. Hunter, M.L. (ed.). 1999. Maintaining Biodiversity in Forest Ecosystems. Cambridge University Press, Cambridge. 698 pp.

4. Scott, J.M. Heglund, PJ, Morrison, M. L., Haufler, J.B., Raphael, M.G., Wall, W.A. and Samson, F.B. (eds). 2002. Predicting Species Occurrences: Issues of Scale and Accuracy. Island Press. Washington, Covelo, London. $868 \mathrm{pp}$.

5. Hannah, L., Carr, J.L. and Lankerani, A. 1995. Human disturbance and natural habitat: a biome level analysis of a global data set. Biodiv. Conserv. 4, 128-155.

6. Perrera, A.H., Euler, D.L. and Thompson, I.D. 2000. Ecology of a Managed Terrestrial Landscape. Patterns and Processes of Forest Landscapes in Ontario. UBC Press, Vandscape. Pattern

Angelstam, P. pp. Sweden. Scand J. For Suppl. L. 2001. Lõhmus, A., Kohv, K., Palo, A. and Viilma, K. Loss of old-growth, and the minimum need for strictly protected forests in Estonia. Ecol. Bull. 51. (in press).

Angelstam, P., Roberge, J.-M., Lohmus, A., Bergmanis, M., Brazaitis, G., Breuss, M., Edenius, L., Kosinski, Z., Kurlavicius, P., Larmanis, V., et al. Habitat modelling as a Ecol. Bull. (In press).

10. Verner, J., Morrison, M.L. and Ralph, C.J. (eds). 1986. Wildlife 2000: Modeling Habitat Relationships of Terrestrial Vertebrates. The University of Wisconsin Press, Madison. 479 pp.

11. Fleishman, E., Jonsson, B.G. and Sjögren-Gulve, P. 2000. Focal species modeling for biodiversity conservation. Ecol. Bull. 48, 85-99.

12. Angelstam, P., Eriksson, J.A., Jaxgård, P., Kellner, O., Koffman, A., Mikusinski, G., Ranneby, B., Roberge, J.M., Rönnbäck, B-I., Rystedt, S. and Seibert, J. Gap Analysis and Planning of Habitat Networks for the Maintenance of Boreal Forest Biodiversity. A Technical Report from the "RESE" Case study in Sweden. Department of Natural Sciences, Örebro University. (In press).

13. Jansson, G. and Angelstam, P. 1999. Threshold levels of habitat composition for the presence of the long-tailed tit (Aegithalos caudatus) in a boreal landscape. Landscape Ecol. 14, 283-290.

14. Angelstam, P. and Breuss, M. (eds) 2001. Critical Habitat Thresholds and Monitoring Tools for the Practical Assessment of Forest Biodiversity in Boreal Forest. Report to MISTRA. (http://iufro.boku.ac.at/iufro/iufronet/d8/hp80206.htm)

15. Mikusinski, G., Gromadzki, M. and Chylarecki, P. 2001. Woodpeckers as indicators of forest bird diversity. Conserv. Biol. 15, 208-217.

16. Roberge, J.-M. and Angelstam, P. Usefulness of the umbrella species concept as a conservation tool. Conserv. Biol. (In press).

17. Musters, C.J.M., de Graff, H.J. and ter Keurs, W.J. 1998. Defining socio-environmental systems for sustainable development. Ecol. Econ. 26, 243-258.

18. Berkes, F., Colding, J. and Folke, C. 2003. Navigating Social-Ecological Systems. Cambridge University Press, Cambridge. (393 pp.)

19. Bossel, H. 2000. Policy assessment and simulation of actor orientation for sustainable development. Ecol. Econ. 34, 337-355.

20. Peterson, G. 2000. Political ecology and ecological resilience: An integration of human and ecological dynamics. Ecol. Econ. 35, 323-336.

21. Turner, R.K., van den Bergh, J.C.J.M., Soderqvist, T., Barendregt, A., van der Straaten, J., Maltby, E. and van Ierland, E.C. 2000. Ecological-economic analysis of wetlands: scientific integration for management and policy. Ecol. Econ. 35, 7-23.

22. Larsson, T.-B., Angelstam, P., Balent, G., Barbati, A., Bijlsma, R.-J., Boncina, A., Bradshaw, R., Bücking, W., Ciancio, O., Corona, P., et al. 2001. Biodiversity evaluation tools for European forest. Munksgaard International Publishers, Copenhagen. Ecol.
Bull. 50, $236 \mathrm{pp}$.

23. Weisbuch, G. 2000. Environment and institutions: a complex dynamical systems approach. Ecol. Econ. 34, 381-391.

24. Anderies, J.M. 2000. On modeling human behavior and institutions in simple ecological economic systems. Ecol. Econ. 35, 393-412

25. Gunderson, L.H., Holling, C.S., and Light, S.S. 1995. Barriers and Bridges to the Renewal of Ecosystems and Institutions. Columbia University Press, New York. $593 \mathrm{pp}$. . Brunction Planning: Resource Management Beyond the New Millennium. Harwood Academic Publishers, Amsterdam. 162 pp.

27. Lee, K N. 1993. Compass and Gyroscope. Integrating Science and Politics for the Environment. Island Press, Washington DC. 243 pp.

28. Bunnell, F.L. and Johnson, J.F. 1998. Policy and Practices for Biodiversity in Managed Forests: The Living Dance. University of British Columbia Press. Vancouver. 162 pp. 253, 758-762.

30. Forester, D.J. and McKendry J.E. 1996. Extending gap analysis to include socioeconomic factors. In: Gap Analysis. A Landscape Approach to Biodiversity Planning Scott, J.M. factors. In: Gap Analysis. A Landscape Approach to Biodiversity Planning. Scott, J.M., Tear, T.H. and Davis, F.W. (eds).

31. Colombo, R., Vogt, J. and Bertolo, F. 2001. Deriving Drainage Networks and Catchment Boundaries at the European Scale. Joint Research Centre, European Commission, Ispra, $56 \mathrm{pp}$.

32. Ecol. Appl. 1993. 3(4). Perspectives on sustainability.

33. Hammer, M. and Söderqvist, T. 2001. Enhancing transdisciplinary dialogue in curricula development. Ecol. Econ. 38, 1-5.

34. Angelstam, P. and Andersson, L. 1997. To What Extent Does the Area of Protected Forest in Sweden Increas to Protect Biological Diversity? (I Vilken Omfattning Behöver Arealen Skyddad Skog $i$ Sverige Utökas för att Biologisk Mångfald Skall Bevaras?) Miljövårdsberedningen, Stockholm. (In Swedish).

35. Fahrig, L. 2001. How much habitat is enough? Biol. Conserv. 100, 65-74

36. Brooks. R.P. 1997. Improving habitat suitability index models. Wildl. Soc. Bull. 25, 163-167.

37. Viilma, K., Öövel, J., Tamm, U., Tomson, P., Amos, T., Ostonen, I., Sorensen, P. and Kuuba, R. 2001. Estonian Forest Conservation Area Network. Ministry of the environment of the Republic of Estonia, Tartu.

38. Forman, R.T.T. 1995. Land Mosaics. Cambridge University Press, Cambridge. 632 pp. 9. Fahrig, L. 1997. Relative effects of habitat loss and fragmentation on population extinction. J. Wildl. Mgmt 61, 603-610.

40. Fahrig, L. 2002. Effect of habitat fragmentation on the extinction threshold: a synthesis. Ecol. Appl. 12, 346-353.

41. McGarigal, K. and McComb, W.C. 1995. Relationships between landscape structure and breeding birds in the Oregon Coast Range. Ecol. Monogr. 65, 235-260

42. Drolet, B., Desrochers, A. and Fortin, M.-J. 1999. Effects of landscape structure on nesting songbird distribution in a harvested boreal forest. Condor 101, 699-704

43. Trzcinski, M.K., Fahrig, L. and Merriam, G. 1999. Independent effects of forest cover 
and fragmentation on the distribution of forest breeding birds. Ecol. Appl. 9, 586-593 . Villard, M.-A., Trzcinski, M.K. and Merriam, G. 1999. Fragmentation effects on forest birds: relative influence of woodland cor

45. Picket, S.T.A. and White, P.S. 1985. The Ecology of Natural Disturbance and Patch Dynamics. Academic Press, New York. 472 pp

46. Lambeck, R.J. 1997. Focal species: a multi-species umbrella for nature conservation. Conserv. Biol. 11, 849-856.

47. Lambeck, R.J. 1999. Landscape planning for biodiversity conservation in agricultural regions: a case study from the wheatbelt of Western Australia. Biodiversity Technical Paper 2. Environment Australia, Canberra, Australia.

48. Angelstam, P., Anufriev, V.M., Balciauskas, L., Blagovidov, A.K., Borgegård, S.-O Hodge, S., Majewski, P., Ponomarenko, S.V., Shvarts, E.A., Tishkov, A.A., et al. 1997. Biodiversity and sustainable forestry in European forests - How west and east can learn from each other. Wildl. Soc. Bull. 25, 38-48.

49. Uliczka, H. and Angelstam, P. 2000. Assessing conservation values of forest stands based on specialised lichens and birds. Biol. Conserv. 95, 343-351.

50. Fleishman, E. Murphy, D.D and Brussard, P.F. 2000. A new method for selection of umbrella species for conservation planning. Ecol. Appl. 10, 569-579.

1. Caro, T. M. Umbrella species: critique and lessons from East Africa. Anim Conserv. (In press)

52. Förstner, W. 1984. Results of Test 2 on gross error detection of ISP WG III/1 and OEEPE. In: International Archives of Photogrammetry and Remote Sensing. Rio de Janeiro, pp. 220-233.

53. Openshaw, S. 1989. Learning to live with errors in spatial databases. In: Accuracy of Spatial Databases. Goodchild, M. and Gopal, S. (eds). Taylor \& Francis, City, pp. 263 276.

54. Rönnbäck B.-I., Nordberg, M.-L., Olsson, A. and Östman, A. 2003. Evaluation of environmental monitoring strategies. Ambio 32, 494-500.

55. Ostrom, E. 1990. Governing the Commons. Cambridge University Press, Cambridge. $288 \mathrm{pp}$

6. Healey, P. 1997. Collaborative Planning: Shaping Places in Fragmented Societies. Macmillan Press.

57. Berkes, F. and Folke, C. 1998. Linking Social and Ecological Systems. Cambridge University Press, Cambridge. $459 \mathrm{pp}$

8. Gunderson, L.H. and Pritchard Jr., L. 2002. Resilience and the Behavior of Large-scale Systems. Island Press, Washington DC. 287 pp.

9. Gunderson, L.H. and Holling, C.S. 2002. Panarchy: Understanding Transformations in Systems of Humans and Nature. Island Press, Washington DC. $507 \mathrm{pp}$.

60. O'Toole, L.J. 1986. Policy recommendations for multi-actor implementation: An assessment of the field. J. Publ. Policy 6, 181-210.

61. Sabatier, P.A. (ed.) 1999. Theories of the Policy Process. Westview, Boulder (CO)

2. Bonnicksen, T.M. 1991. Managing biosocial systems: a framework to organize societyenvironment relationships. J. For. 89, 10-15.

63. Rauscher, M.H. 1999. Ecosystem management decision support for federal forests in the United States: A review. For. Ecol. Mgmt 114, 173-197.

64. Whiting, K. 2000. Revised Principles and Guidelines for National Forest Programmes (draft for discussion). Forest Programmes Coordination and Information Initiative, Food and Agriculture Organization of the United Nations, Rome.

65. Worrell, A.C. 1970. Principles of Forest Policy. McGraw-Hill

6. Merlo, M, and Paveri, M. 1997. Formation and implementation of forest policies: A focus on the policy tools mix. In: Policies, Institutions and Means for Sustainable
Forestry Development 5, Proc. XI World Forestry Congress, 13-22 October 1997, Forestry Development 5 , $\mathrm{Pr}$

67. Olson, M. 1971. The Logic of Collective Action. Harvard University Press, Cambridge and London.

68. Olson, M. 1982. The Rise and Decline of Nations. Yale University Press, New Haven and London.

69. Bates, R.H. (ed.). 1988. Toward a Political Economy of Development: A Rational Choice Perspective. University of California Press, Berkeley, Los Angeles, London

70. Angelstam, P. and Pettersson, B. 1997. Principles of present Swedish forest biodiversity management. Ecol. Bull. 46, 191-203.

1. Stjergent. P. 1991-1992 Forest Treatment - Relations to Nature of Swedish Private Forestry. Kungliga Humanistiska Vetenskapssamfundet, Lund, Sweden.

Hiern, B. and Po r. D. 1981. Implementation structures A new unit of administate analysis. Organis. Stud 2 pp-ppxx.

analysis. Organis. Stud. 2, pp-ppxx.

Soconomy of Local Economic Policy. A Comparative Näringspolitikens Politiska (In Swedish).

74. Bogason, P. and Sörensen, E. 1998. Community Research Bottom-up: Theory and Methods. (Samfundsforskning Bottom-up: Teori og Metode). Roskilde Universitetsforlag, Roskilde. (In Danish). a.Lundquist, L, 1987.

Studentlitteratur,

75. Vogt, K.A., Grove, M., Asbjornsen, H., Maxwell, K.B., Vogt, D.J., Sigurdardottir, R. Larson, B., Schibli, L. and Dove, M. 2002. Linking ecological and social scales for natural resource managen Resource Management Liu, J and Taylor W. (eds). pp.143-175.

76. World Wide Web Consortium 2002. Web services glossary - W3C working draft 14 November 2002. (http://www.w3.org/TR/2002/WD-ws-gloss-20021114/)

77. JRC 2002. INSPIRE - News and events. (http://inspire.jrc.it/)

78. Helms, J.A. (ed.) 1998. The Dictionary of Forestry. Society of American Foresters and CABI Publishing, Oxon

79. Bormann, B.T., Martin, J.R., Wagner, F.H., Wood, G.W., Alegria, J., Cunningham, P.G., Brookes, M.H., Friesema, P., Berg, J. and Henshaw, J.R. 1999. Adaptive management. W.T., Malk, A.J., Szaro, R.C. and Johnson, N.C. (eds). Elsevier Science, pp. 505-534.

80. Shindler, B., Cheek, K.A. and Stankey, G.H. 1999. Monitoring and Evaluating Citizenagency Interactions. A Framework Developed for Adaptive Management. Report No PNW-GTR-452, Pacific Northwest Research Station, USDA Forest Service, USA

81. Liu, J. and Taylor, W.W. 2002. Integrating Landscape Ecology into Natural Resource Management. Cambridge University Press, Cambridge.

82. Angelstam, P. 2002. Reconciling the linkages of land management with natura disturbance regimes to maintain forest biodiversity in Europe. In: Landscape Ecology and Resource Management: Linking Theory with Practice. Bissonette J.A. and Storch I., (eds). Island Press, Covelo CA and Washington, DC. pp. 199-226.

83. Sandström, U.G., Khakee, A. and Angelstam, P. The need for integrating landscap ecology with planning a case study of Swedish urban planners. In: Local Resistance to Global Pressure: A Mediterranean Social/Environmental Planning Perspective Barbanente A., Borri D., Camarda D., Grassini L. and Khakee A. (eds). Paris, L'Harmattan. (In press).

84. Lazdinis, M. 2002. Facilitating Sustainable Forest Development: Comparative Analysis of Post-Soviet Forest Politics in the Baltic States. Ph.D. Dissertation.
Department of Geography, Southern Illinois University Carbondale. USA. $387 \mathrm{pp}$.
Per Angelstam is an ecologist with a an interest in applying knowledge in practical land-use management. Currently, he is studying the effects of landscape change on biodiversity at multiple spatial and temporal scales in boreal and mountain forests with different management and histories (www.bornet.org). He is also working with land managers to develop targets to assess and tools communicate to the status and trends of different elements of biodiversity in forests and ancient cultural landscapes.

per.angelstam@nvb.slu.se

Grzegorz Mikusiński is a researcher at the Swedish University of Agricultural Sciences. His main interest concerns the relationships between landscape composition and biological diversity. He is also a lecturer in landscape ecology at Örebro University.

grzegorz.mikusinski@nat.ore.se

Their address: Örebro University, Department of Natura Sciences Centre for Landscape Ecology, SE-701 82 Örebro, Sweden.

Britt-Inger Rönnbäck is a PhD student at the Division of Geographical Information Technology, Luleå University of Technology. She has an MSc in surveying, and a licentiate degree in geographic information technology. Before joining Luleå University of Technology she worked as a software developer and system analyst at the Swedish Space Corporation and at the Swedish Land Survey. She is planning to defend her PhD thesis winter 2004. The thesis concerns spatial data quality and data usability. Her address: Department of Environmental Engineering, Geographical Information Technology, Luleå University of Technology, SE-971 87, Luleà, Sweden.

britt-inger.ronnback@sb.luth.se

Anders Östman is a professor at the Division of Geographic Information Technology, Luleå University of Technology, and the head of the division. He has an MSc in surveying and a $\mathrm{PhD}$ in photogrammetry. He has also worked for Intergraph, an American GIS software vendor. Since 1993, he has gradually established the research and educational facilities in GIS at Luleå University of Technology, where he received a full professorship in 1997. His research concerns spatial data quality. His address: Department of Environmental Engineering, Geographical Information Technology, Luleå University of Technology, SE-971 87, Luleå, Sweden. anders.ostman@sb.luth.se

Marius Lazdinis completed his Masters degree in forest protection at Lithuanian Agricultural University. Before starting his PhD in Southern Illinois University, USA, he worked for the Lithuanian Ministry of Environment and was responsible for international cooperation in the forest sector. Since completion of a PhD in policy science at Southern Illinois University, USA, he has been a doctoral student in ecology at Department of Conservation Biology at the Swedish University of Agriculture. His address: Swedish University of Agricultural Sciences, SE-901 83 Umeà, Sweden.

marius.lazdinis@nvb.slu.se

Jean-Michel Roberge is a forester with a strong interest for forest ecology and biodiversity conservation. He graduated in 2001 from Université Laval, Canada, with a BSc in forest management and environment. He is currently completing PhD studies in ecology at the Department of Conservation Biology, Swedish University of Agricultural Sciences, working on the use of specialised birds' requirements as a tool for forest conservation planning. His address: Swedish University of Agricultural Sciences, SE-901 83 Umeå, Sweden. jean-michel@nvb.slu.se

Wolter Arnberg, PhD, Program coordinator. His address: Stockholm University, Department of Physical Geography SE-106 91 Stockholm, Sweden arnberg@natgeo.su.se

Jan Olsson is PhD and Associate professor in political science at Örebro University. His research focus is on policy and implementation in complex settings, such as multi-level governance and private-public cooperation. Olsson also has an interest in issues on democracy and democratic renewal, especially in relation to the policy process. His address: Department of Social Sciences, Novemus, Örebro University, SE-701 82 Örebro, Sweden.

jan.olsson@sam.oru.se 